certainly increased my general medical knowledge, while giving a more realistic cross-section of psychiatric illnesses. The GPs were pleased to have a physician with a psychiatric background, and referred a large number of their patients to me. Consequently, the percentage of "straightforward, successful" treatments was considerably higher than the more difficult cases who tended to become psychiatric out-patients or in-patients. I was also able to impart some of my clinical skills to my colleagues.

For myself, I acquired a different perspective and a considerable amount of useful experience which has been very helpful when coordinating treatment with other specialists. I am currently employed in a health maintenance organisation of managed medical care, Group Health, and as a geriatric specialist with the local community mental health centre in Kitsap County, Washington State. Both these positions are out-patient oriented, with minimal hospitalisation, and my background in general practice has been very helpful. By way of comparison, some of my American psychiatric colleagues have much greater experience in training in the psychotherapies, but sometimes this was at the expense of general medical experience. Eventually, one hopes, a satisfactory blend of training will be achieved for most general psychiatrists, with additional training in specialised areas.

Group Health Cooperative of Puget Sound

SHARON CARTER

Bremerton, WA 98312

USA

\section{Health Service staffing in child and adolescent psychiatry}

DEAR SIRS

In 1987 the North East Thames Child and Adolescent Psychiatrists Committee began to collect data on manpower within Child and Adolescent Psychiatric Departments and Child Guidance Clinics within the region to look at the levels of staffing and trends. There was a great deal of concern about the gradual erosion of staff from the service at a time of increasing demand on the specialty. Dr Black's paper on consultant manpower in the region (Psychiatric Bulletin, January 1989, 13, 32-35) outlines areas of particular increased demand, e.g. child sexual abuse, effects of marital breakdown, forensic work, liaison services, drug abuse, child care proceedings, etc.

At the same time changes have taken place in the organisation of other disciplines which in the past had a major role in service provision within child and adolescent psychiatry or child guidance. Educational Psychologists are now almost exclusively employed within the School Psychological Service with a resultant loss of their clinical time. The loss of the Psychi- atric Social Worker and the frequent employment of generically trained social workers under direct social services management being placed in clinics has meant a change in the nature of their input. In many instances posts have been lost, for example in West Essex four out of six posts. There has been no corresponding increase in manpower provision by the Health Service whose contribution has remained largely static, at least since 1984, the earliest year for which I have figures. In December 1988 there was an establishment of 36 consultant posts for the region, population 3.75 million (one post per 140,000 population). There were seven WTE consultant posts vacant for over four months, some as long as two years. In one district a locum has been in post for 14 years. One of the Regional Adolescent In-patient units is closed; there is no alternative provision in the interim until it reopens. This has resulted in the loss of 20 beds and staff.

Only 10 out of 16 districts have any junior staff. Of these, only three have both senior registrar and registrar, two a senior registrar only, four a registrar only and six neither.

There is very little manpower to support the consultant sessions. The next largest group of professionals in this region are child psychotherapists (27.2 whole time equivalents) who may or may not be organised in the district to work together with the consultant. Regionally there are also 1.5 WTE clinical assistants, 2.4 WTE clinical psychologists, 7 CPNs, 26.5 nurses and 11.3 administrative staff. (These figures do not include services provided by two Special Hospital Authorities geographically located within the Region.)

This is a specialty struggling to meet an increasing demand on its time with decreased resources, making an increasing burden on fewer staff. Given that 10$20 \%$ of children suffer from psychiatric disturbance depending on whether they live in rural or inner-city areas, the resources compare very poorly with those available for adult mentally ill or physically ill children.

North Middlesex Hospital

T. NAIDOO London N18 1QX

\section{Local Government Finance Act, 1988 -mental impairment and poll tax}

\section{DeAr Sirs}

Most general practitioners and psychiatrists are, sooner or later, going to be confronted with the dilemma of certifying someone as suffering from severe mental impairment at the request of Community Charges Registration Officer in respect of a person who is seeking exemption from liability to 
pay personal community charge or Poll Tax on the grounds of "Severe Mental Impairment".

According to the Local Government Finance Act, 1988 (LGFA 1988) severe mental impairment is defined as:

(a) a state of arrested or incomplete development of mind which involves severe impairment of intelligence and social functioning, or

(b) an injury to the brain causing severe impairment of intelligence and social functioning which appears to be permanent.

The definition now includes mental illness and dementia. If the certifying doctor is in doubt he is expected to get information and advice from an appropriate medical colleague or colleagues in other professions.

To be exempted from the Poll Tax the certification of severe mental impairment alone is not sufficient; one has to be in receipt of such benefits as: invalidity pension; severe disablement allowance; unemployability supplement; unemployability allowance payable to civilians or armed forces; attendance allowance or constant attendance allowance.

Having got used to the MHA definition of severe mental impairment, we now find there is another definition. Conceivably a doctor could refuse a medical recommendation according to the MHA definition but certify the same person as suffering from severe mental impairment for Poll Tax purposes. The situation will become worse if a psychiatrist refuses to sign on the grounds of the MHA and the GP signs it on the grounds of the LGFA.

The term "Severe Mental Impairment" is only used now for MHA purposes in the presence of abnormally aggressive and seriously irresponsible conduct. The current preferred term is "Learning Difficulty" or "Learning Disability".

As we are trying to go away from "Severe Mental Impairment" (except when MHA, 1983 is applicable), if one includes the mentally ill, the brain damaged and the elderly mentally ill in that category, there is likely to be resentment from these groups of people diagnosed as Severe Mental Impairment according to the LGFA.

This would also create hardship for people with conditions that would make them Severely Intellectually Handicapped or Socially Handicapped but not both, as it is a requirement that one should suffer from both to qualify for Severe Mental Impairment according to the LGFA. For example, a Down's Syndrome sufferer with severe intellectual handicap but not social handicap; an autistic sufferer with severe social handicap but not intellectual handicap, and a chronic schizophrenic sufferer with severe social handicap but not intellectual handicap. The same goes for people who suffer chronic depression and the elderly mentally ill who could suffer some intellectual impairment but not social impairment. All these people would not be automatically excluded from Poll Tax but they would be entitled to if they had been living in hospitals, nursing homes, or residential care homes or hostels. Even though most of them will be in receipt of one or more of the allowances mentioned, this group of people will not be qualified for exemption from Poll Tax.

It is assumed that people on low incomes are entitled to claim rebates of their Poll Tax payment to a maximum of $80 \%$. Even if it is granted that all these people are going to get an $80 \%$ rebate it is wrong to expect them to pay the $20 \%$ of the Poll Tax simply because they have a caring relative or friend.

On the contrary, a recent communication from Duncan Nichol-Caring for People: Community Care in the Next Decade and Beyond: Questions and Answers (6) says "However well we provide social care in hospital settings it is rarely where people choose to live. The changes will ensure more people are able to choose to remain in or return to their own homes, whether during periods of temporary crisis or when they need long term support." By not giving a group of deserving people exemption it looks as if the right hand says something without knowing what the left is going to do.

I recommend that the term "Severe Mental Impairment" be withdrawn from the LGFA, 1988 as it appears already in the MHA where it is defined quite differently. Furthermore automatic exemption should be given for people who are cared for in the community by relatives or friends if, in the doctor's clinical judgement:

(a) the applicant's social functioning and/or intelligence are severely impaired because of arrested or incomplete development of mind, mental illness or dementia, whether resulting from brain injury or other causes, and that the impairment appears to be permanent, and

(b) those who are in receipt of one of the above allowances, as I understand almost all these people would be qualified for one form of allowance or other.

K. NADESAlingham

Unit of Services for People with Mental Handicap

Church Hill House Hospital

Bracknell, Berkshire RG12 4EP

\section{Reference}

Nichol, D. (1989) Caring for People: Community Care in the Next Decade and Beyond: Questions and Answers. EL(89)MB202. NHS Management Executive, 16 November 1989. 